\title{
Effects of the Built Environment on Childhood Obesity: the Case of Urban Recreational Trails and Crime
}

\author{
Robert Sandy\#, Rusty Tchernis*, Jeff Wilson‡, Gilbert Liu\#\#, and Xilin Zhou ${ }^{\dagger}$ \\ \#Department of Economics, IUPUI \\ *Department of Economics, Georgia State University, IZA and NBER \\ FDepartment of Geography, IUPUI \\ \#\#Department of Pediatrics, Indiana University School of Medicine \\ tDepartment of Economics, Georgia State University
}

\begin{abstract}
We study the effects of urban environment on childhood obesity by concentrating on the effects of walking trails and crime close to children's homes on their BMI and obesity status. We use a unique dataset, which combines information on recreational trails in Indianapolis with data on violent crimes and anthropomorphic and diagnostic data from children's clinic visits between 1996 and 2005. We find that having a trail near a home reduces children's weight. However, the effect depends on the amount of nearby violent crimes. Significant reductions occur only in low crime areas and trails could have opposite effects on weight in high crime areas. These effects are primarily among boys, older children, and children who live in higher income neighborhoods. Evaluated at the mean length of trails this effect for older children in no crime areas would be a reduction of two pounds of the body weight. Falsification tests using planned trails instead of existing trails, show that trails are more likely to be located in areas with heavier children, suggesting that our results on effects of trails represent a lower bound.
\end{abstract}

\section{Keywords}

Childhood obesity; built environment; crime

\section{Introduction}

The extent and the dire health consequences of the U.S. child obesity epidemic are well documented (Anderson and Whitaker, 2009, Hannon et al., 2005). The alarming growth in child obesity has generated many proposals for interventions, some of which have been implemented at local and state levels. These proposals have been primarily aimed at schools and food sellers. They include: state and national taxes on sugared soft drinks (Salant, 2009); bans on such drinks in schools (Price, 2006); bans on building new fast food restaurants, increases in mandatory physical education requirements; and healthier school lunch menus (Trust for America's Health, 2009). Many of these proposals have been made without sufficient evidence that they would have a beneficial effect or in spite of evidence

Publisher's Disclaimer: This is a PDF file of an unedited manuscript that has been accepted for publication. As a service to our customers we are providing this early version of the manuscript. The manuscript will undergo copyediting, typesetting, and review of the resulting proof before it is published in its final citable form. Please note that during the production process errors may be discovered which could affect the content, and all legal disclaimers that apply to the journal pertain. 
that they would have no benefit. Doubts about the effectiveness of specific mechanisms for countering child or adult obesity have been raised by: Cawley et al. (2007) on physical education classes; Millimet et al. (2010) on changing school lunch programs; Sandy et al. (2011) and Anderson and Matsa (2011) on bans on new fast food restaurants; and, Whatley Blum et al. (2008) on banning sugared soft drinks.

There have been proposals to use differential health insurance pricing to reduce adult obesity (Johnson, 2009). For adults with any health insurance, an obesity surcharge on their health insurance premium is similar to a direct tax for being obese. The application of such proposals to children has been met with strong resistance. Even if differential health insurance pricing were to improve parents' child-rearing behavior and reduce child obesity, it is unlikely to be politically feasible. An incident that occurred in October of 2009 illustrates the public's highly negative reaction. A private insurer, the Rocky Mountain Health Plan, refused to sell health insurance to a Colorado family on the grounds that the family's four-month old baby was obese (Lofholm, 2009). Within two days a tsunami of national unfavorable publicity caused the company to reverse its decision (Sandell, 2009). It is similarly difficult to find politically feasible policies to reduce children's at home sedentary activities, such as television viewing or playing video games. Obesity report cards, i.e. reports on the child's BMI percentile sent from schools to a child's parents, are an example of a policy designed to reach into the child's home. Obesity reports cards have generated a great deal of resistance (Kantor, 2007). The political landscape may be shifting toward an increased receptiveness to within-the-family interventions. For example, in a commentary in the Journal of the American Medical Association, Murtagh and Ludwig (2011) urged the consideration of transfer of approximately two million morbidly obese children to foster care. The author's rationale was that being beyond the 99th percentile for BMI indicated unfavorable home circumstances that were so threatening as to merit removal from their parents' care. A second "straw in the wind" was a suggestion in March of 2011 by Illinois State Senator Shane Cultra that families with obese children lose their state child income tax deduction (Hess, 2011). It is not clear that these proposals targeting families and home environments are politically feasible. They may merely be indicative of the frustrations with current policies, or serve as ploys to garner attention to a worsening public health menace.

Reversing the child obesity epidemic will require policies that are both effective and politically feasible. A broad category of potential interventions entails changing the built environment to promote healthier eating and increase physical activity. Subsidies for, or public provision of, potentially weight-reducing built amenities would be potentially easier to implement than in-home interventions. An additional advantage of weight-reducing built environment interventions is that they have smaller negative spillovers on individuals who are at healthy weights. While individuals who are in a healthy weight range would be taxed to support changes in the built environment, such as recreational amenities, the non-obese appear to be at least as likely to use these amenities. In contrast, taxes on sugared soft drinks and bans on fast food restaurants impact non-obese individuals without giving them a direct benefit.

Proposals for altering the built environment run the gamut from modifying streets to encourage walking, to constructing recreational amenities as pools, soccer fields, basketball courts, and trails, to zoning laws requiring mixes of residential and commercial land use, to locating schools within walking distance of the homes (King et al., 1995, Sallis, 1998, Margetts, 2004). Proposals addressing the built environment are also running well ahead of the evidence. Although the American Academy of Pediatrics Committee on Environment recommends that policymakers: "Fund research on the impact of the built environment at neighborhood and community levels on the promotion of overall health and active lifestyles 
for children and families" the committee surprisingly does not suggest such research be completed before it goes on in the same report to recommend a host of interventions that have little empirical support (Committee on Environmental Health, 2009).

A crucial problem for identifying public policies that can counter the child obesity epidemic via the built environment is the endogeneity of household and amenity location choices.

Households who chose to live near an amenity would be expected to have stronger preferences for that amenity. Moreover, the locations of public recreational amenities are a political decision that can be influenced by the lobbying of the households most interested in using the amenity. Thus, cross-sectional studies of built environment may reveal more about the preferences of the families who live near an amenity than they reveal about its impact. Private companies, such as fast food restaurants, place outlets where, ceteris paribus, they expect to have the most customers. An example of this endogeneity problem is the conclusion, formed on the basis of many cross-sectional studies, that urban sprawl contributes to obesity. This result was not supported in either a study of people who moved between cities with different levels of sprawl (Plantinga and Bernell, 2007) or in a study of changes in the level of sprawl over time in a given city (Ewing et al., 2006).

The amenity that is the subject of this paper, recreational trails, presumably attracts families to locate nearby who value a trail as an exercise opportunity. It is reasonable to assume that these households would most likely have healthier diets and engage in more exercise than the average household, even without a nearby trail. Absent the random assignment of residential location, such as the Moving to Opportunity Experiment (Kling, 2004), an ideal research design is to either have an instrument that predicts location but not BMI or a natural experiment that moves households or amenities. Since body weight is influenced by so many factors, it is difficult to find a plausible instrument. Some natural experiments that have moved many households, e.g. Hurricane Katrina, also change other factors that are related to body weight; for example, individuals displaced by natural disasters could experience depression, psychological stress, or impaired sleep, all of which would complicate discerning how new recreational amenities would contribute to changes in their weight status.

In this paper we investigate the effects of urban recreational trails on child weight status. The trails could potentially reduce the cost of exercise due to lower time and money cost (e.g. compared to costs of gym memberships), and, for individuals who prefer exercising outdoors, trails can also increase the marginal utility of exercise. Both of those effects should lead to more exercise and potentially lower weight. However, one needs to consider the potential use of trails, particularly in inner-city environments. In high crime areas, trails may facilitate criminal activity by providing more targets for criminals and/or a means of escape or of blending in with other users. Fear of crime has been associated with reduced physical activity, and so trails that increase crime could subsequently lead to higher rates of child obesity. Thus, it is not clear a priori what the total effect would be and whether this effect would depend on the amount of crime in the area.

We take advantage of the fact that the recreational trails in the City of Indianapolis had to be located on city owned land along an abandoned rail line, along streams and rivers, or along a canal towpath. These requirements sharply limited the usual political influence in public amenity locations. Also, given the short times between their announcement and construction of trails ${ }^{1}$, these trails could not have been factored into the location choices of most of the families who live nearby. For example, the largest and most heavily used trail, the Monon trail, was not abandoned as a rail line until 1987. To have changed the unobserved preferences prior to the advent of the trail toward households that favored exercise, 
households that viewed the abandoned rail line as a recreation opportunity would have had to moved nearby between 1987 and 1995, when the first segment of Monon trail was built.

In spite of these advantages, the possibility remains that households might have chosen to reside near the abandoned rail lines, along streams and rivers, or along canal towpaths because they value these as outdoor recreation opportunities. However among trails in Indianapolis, which are depicted in Figure 1, the canal towpath trail is the only gravel path in the system, and it is the only one that functioned as a recreational opportunity prior to the creation of the trail system. As for the sites of the other trails, the recreational opportunities were minimal before the trail system was built. The riparian sites that eventually developed into trails had no path before the trail system was built. Their attractiveness for other forms of water recreation, such as fishing and canoeing, were limited by the city's practice of using them as overflow dumps for raw sewage. These long public recreational trails appear more likely to be exogenous than amenities that serve households that live near a specific location, such as a jungle gym in a mini park. Sandy et al. (2011) attempt to simultaneously estimate the effects of seventeen amenities on children's BMI. Among the seventeen amenities, they found (pps. 209-211) that trails, based on the absence of differences in BMI trends prior to the trail arrivals, were among the least likely to have locations dictated by either neighborhood politics or private information related to preferences of residents in the neighborhood. An additional advantage of studying these trails is that they run through a variety of areas in terms of income, housing types, and land use.

Our study uses a dataset that combines clinical data on children, geographical data on the location of children's home addresses and locations of trails, as well as data and locations of violent crimes in the city of Indianapolis. We utilize a sample of approximately 97,000 observations on children's BMI for approximately 37,000 children. The research plan considered a fixed effects model to estimate the impact on BMI of a trail being created near a given child's home; however, we had inadequate numbers of pre and post BMI measures for children who gained a trail while residing at the same address. Instead, we use fixed effects at the census tract level.

We find that trails have a beneficial effect on reducing children's weight, but any beneficial effects of a recreational trail depended on the nearby rates of violent crime. In addition, violent crimes alone appear to significantly raise children's weights, with or without a nearby trail. While we are not sure if that is the direct effect of crime or other characteristics of areas with more crime, we view these findings as important. Also, the weight gains associated with nearby crimes are strongest for younger children and for girls.

The balance of the paper is organized as follows: Section 2 reviews the literature on the weight effects of the built environment; Section 3 describes data used in this paper; Section 4 explains the estimation strategy and results; and Section 5 concludes.

\section{Literature Review}

The model of "obesogenic environment" proposes a causal relationship between environmental characteristics and obesity (Egger and Swinburn, 1997, Hill and Peters, 1998, Poston and Foreyt, 1999, Swinburn and Egger, 1999). Contemporary literature is generally concerned with two aspects of the causal relationship. One set of studies focuses on the influences of the physical, or 'built' environment (transportation, physical activities

\footnotetext{
${ }^{1}$ According to Lindsey et al. (2008), the city largely ignored the Kessler plan from 1908, as it built freeways and expanded neighborhoods. When the city revived the Kessler plan in 1994 to create a system of recreation trails, the character of the areas planned in 1908 had obviously changed. The result according to Lindsey et al. (2008) was that "the poor and minorities have disproportionate access to trails" (p. 59).
} 
facilities, and local food environment etc.) on obesity (Ewing et al., 2006, Booth et al., 2005, French et al., 2000). Another set of studies concentrates on the impact of socioeconomic deprivation of the community, or other factors related to the social environment on obesity (Oliver and Hayes, 2005, Liu et al., 2002, Gordon-Larsen et al., 2006).

Among aspects of the environment that may influence an individual's risk for obesity, one key factor is the effect of neighborhood characteristics that are unfavorable for physical activities. Modern urban design has largely been oriented towards facilitating automotive transportation (Saelens et al., 2003, Frank et al., 2004, Ewing et al., 2003, Jackson and Kochtitzky, 2003). This focus on motorized transit brings convenience while promoting a sedentary lifestyle (Nelson and Gordon-Larsen, 2006, Boone et al., 2007), and in many instances creating substantial barriers to non-motorized transit.

Many studies have investigated the relationship between built environment characteristics and obesity. Burdette and Whitaker (2004) explored the bodyweights of low-income children in a cross-sectional study. They found that accessibility of playgrounds and fast food restaurants, and the level of neighborhood safety had no association with children's overweight status. Hinkley et al. (2008) reviewed articles investigating the determinants of preschool children's physical activities, and found that BMI had no association with physical activities. Sen et al. (2011) utilized mothers' self-reported measures of neighborhood quality to examine whether there was any relationship between children's BMI and the built environment. They found that overall neighborhood quality did not significantly relate to children's bodyweight. However, their results showed that mothers' perception of neighborhood safety had important influences on children's BMI. Taken in sum, these mixed results from multiple studies suggest that relationships between built environment factors, health behavior such as physical activity, and risk of child obesity are complex, differ from those observed in adults, and remain poorly understood.

Sandy et al. (2011) used a panel dataset of clinical records to investigate whether changes in nearby physical or social environmental factors could be the reason for changes in children's weight. This study was distinguished from those described above in that the panel data enabled analyses of changes in weight that perhaps could be attributed to changes in the environment. They found that some recreation amenities, including fitness areas, kickball diamonds, and volleyball courts, helped to reduce children's BMI. Stafford et al. (2008) utilized a structural equation modeling approach to explore the causal relationship between neighborhood characteristics and obesity. They found that BMI was negatively related to physical activity participations, though they couldn't claim that this correlation was causal. In 2006 Gordon-Larsen et al. found in a cross-section analysis that, children who grew up in neighborhoods with more recreational facilities within a 5-mile buffer around the child's home had a lower probability of being overweight. Many researchers agree that living in a walking-friendly neighborhood was beneficial to residents' health by promoting increased physical activity (Li et al., 2005, Giles-Corti et al., 2003).

The utilization of community facilities is closely related to neighborhood safety. According to a report concerning neighborhood safety and physical inactivity by the CDC (Weinstein, Feigley et al., 1999), residents are significantly less active in less safe neighborhoods than residents are in more safe neighborhoods. Neighborhood insecurity impedes physical activity (Romero et al., 2001, Duncan et al., 2009). Even without considering the use of recreational amenities, safety could be considered to be an independent factor that correlates with obesity. Parents' perceptions of sound neighborhood safety are associated with less obesity risk (Lumeng et al., 2006, Burdette, Wadden and Whitaker, 2006). 
The present study singles out recreational trails as a particular environmental factor, which may correlate with increased physical activities. As stated in the previous section, an advantage of studying urban trails as a built environment intervention to address obesity is that the allocation of trails in Indianapolis may have been exogenous to many households' decisions regarding where to live. As depicted in Figure 1, most trails within Indianapolis locate along the available waterways, except those along the western and eastern boundaries of the county, which are thinly populated. There is also one trail placed on an unused railroad track which is the vertical trail segment labeled as the Monon Trail.

Another advantage to studying trails is their popularity, and their commonly agreed positive effects on promoting walking and cycling (Merom et al., 2003, Librett et al., 2006). Trails are being heavily used in Indiana (Lindsey et al., 2002). The Monon Trail has been described as perhaps the most heavily used urban recreational trail in the United States (Ottensmann and Lindsey, 2008, Reynolds et al., 2007). If urban trails have a protective effect against obesity, one would expect this study to be particularly suitable for identifying such an effect given the high traffic on urban trails that we examined. Moreover, findings from this study are likely to inform policy and urban development in numerous US cities that are looking to expand urban trail networks.

\section{Data}

We use a unique dataset, which combines data from children's clinic visits, their home addresses, the locations of recreational trails, and the locations of violent crimes. The main sources of our data are: (1) electronic medical records from pediatric ambulatory visits to the Indiana University Medical Group between 1996 and 2005; (2) data used for Uniform Crime Reporting to the US Department of Justice, based upon information from the Indianapolis Police Department and the Marion County Sheriff's Department; (3) city data on the initial year and the length of trails within a quarter mile of the child's home. These data sources are described in more detail below.

\section{(1) Clinical records}

The Regenstrief Medical Records System (RMRS) has been in existence since 1973. It has now captured and stored 660 million temporal observations for over two million patients. Because RMRS data are both archived and retrievable, investigators may use these data to perform retrospective and prospective research. RMRS supports physician order entry, decision support, and clinical noting, and is one of the most sophisticated and most evaluated electronic medical record systems in the world.

Using the RMRS, we identified medical records in which there are simultaneous assessments of height and weight in outpatient clinics for children ages 3-18 years inclusive. For these clinic visits, we extracted the visit date, birth date, sex, race, insurance status, and visit type (e.g. periodic health maintenance versus acute care). Height and weight measurements are routinely performed as part of pediatric health maintenance. The data generated by pediatric visits in the RMRS include higher representation of low-income and minority households compared to the demographics of the study area because the associated clinics include the county hospital, Wishard Health Care, which has a specific mission to care for underserved populations.

The initial age range of subjects in this study was three to eighteen years. National guidelines for well-child visits advocate annual visits between ages 3-6 years and at least biannual visits thereafter. However, we observed much more frequent well-child visits for girls age 16 or above than for boys, presumably because the former often use these visits to obtain gynecologic care, such as obtaining prescriptions for birth control drugs. After we 
discovered this gender imbalance in numbers of visits, we restricted the analysis to children in range of ages of 3\#x02013;16. In addition, we extracted ICD-9 codes or other diagnoses list data for identifying children who may have systematic bias in growth or weight status (i.e. pregnancy, endocrine disorders, cancer, congenital heart disease, chromosomal disorders, and metabolic disorders), and excluded observations for such children. We also excluded patient encounters prior to 1996 because the RMRS did not archive changes in addresses data before this date.

\section{(2) Recreational Trails}

The Indianapolis Parks and Recreation Department provided data on the opening date of each segment of each trail. The opening dates are all recent. Thus, it is highly unlikely that much of the pattern of residential location we observe in clinic visits shortly after the trails open was influenced by the presence of a trail. The summary of trails availability is presented in Table 1. We can see that between 1995 and 2006 the city of Indianapolis gained around 50 miles of trails with major trails openings taking place in years 1997 and 1998.

Trail access metrics-We created a measure of the length of any trails, assigned the variable name 'trails4', scaled per 100 meters, within a circle with a of radius 0.25 miles centered on the child's home. The minimum value for this variable was 0 for children represented by the light gray dots or light gray shading in Figure 2. The mean length across all children with or without a nearby trail was 0.122 , i.e. 12.2 meters. The maximum length was 8.44 , i.e. 844 meters. We also created a variable that measured the length of any planned but not yet constructed trails, again scaled per 100 meters. This variable takes the value zero when no trail was planned or when a trail already exists.

There is no established metric for representing trail availability. It is not clear that living immediately adjacent to a trail that follows a straight line provides any less of a recreational opportunity than living immediately adjacent to a trail that follows a zigzag path. Our length-within-a-circle metric treats a zigzagging trail as providing more recreational opportunity than a straight-line trail when both are adjacent to the child's home. However, most of the children who live near a trail are near segments that are reasonably approximated as a straight line. To get a sense of how circles of 0.25 -mile radius would fit in to Figures 1 and 2, Indianapolis is approximated by a square of 20 miles on each side. Thus, even the trails along winding paths next to rivers are reasonably approximated by a straight line within these small circles.

We experimented with different metrics including a dichotomous variable for having any trail and a count for the number of trails (some children lived near intersections of trails). The distance within the circle metric performed better than the dichotomous or count-based variables. We also examined the square of the length of trail segments within buffers to see if there was a non-linear effect to length of nearby trails. It was not significant in any specification. We have approximately 6,492 BMI observations on approximately 1,800 children who had a trail within a quarter mile of their residential address.

Figure 1 shows the locations of trails in the city of Indianapolis. Figure 2 shows the locations of children's residences superimposed on the trails from Figure 1. A dark gray dot indicates a single residence within a quarter mile of a trail. And shaded dark gray areas indicate groups of residences within a quarter mile of a trail that are too close to each other to individually distinguish. The light gray dots and shaded areas are individual residences and groups of residences outside of the quarter mile buffer. To make it impossible to identify actual addresses, each dot on the map was randomly shifted a small distance. The statistical analyses utilized variables derived from data regarding the geocoded point locations of patient residences. 


\section{(3) Crime data}

During the study period, the primary law enforcement responsibility for Marion County was divided between multiple entities, including 1) the Indianapolis Police Department (IPD), which had responsibility for the area within the original Indianapolis boundary; 2) the Marion County Sheriff's Department (MCSD), which had responsibility for most of the outlying areas of the county; and 3) the police departments of the four small municipalities of Speedway, Lawrence, Southport, and Beech Grove which are within the county boundaries but separately incorporated. When the city limits of Indianapolis were expanded to the border of Marion County in 1970, the original police jurisdictions were not affected. In 2007, the Indianapolis Police Department and the Marion County Sheriff's Department were merged into the Indianapolis Metropolitan Police Department.

From the Indianapolis Police Department, for the IPD service area in which they had primary responsibility, we have a dataset of the geocoded locations of all crimes reported for the Federal Bureau of Investigation's Uniform Crime Reports (UCR), from 1992 through 2005. From the Marion County Sheriff's Department, for the area in which they had primary responsibility, we have a dataset on the point locations of a wide range of crimes and other incidents, including the UCR crimes, from 2000 through 2005. For these analyses, we only included information on crimes that are included in the UCR violent crime categories: criminal homicides, rapes, robberies, and aggravated assaults. The dataset includes the date and time of the crime, and more detailed information on the specific type of crime within each of those four categories. Because UCR data regards known offenses and persons arrested by law enforcement agencies, we have reason to believe that these are accurate locations and that the classification of the type of crime is accurate.

To summarize, we have the following coverage for violent crimes:

1. Up through 1999, for the IPD service area only.

2. From 2000 through 2005 , for both the IPD service area and the MCSD jurisdiction.

Unfortunately, we were unable to obtain crime data regarding the study period for the jurisdictions of the four small excluded municipalities that are within Marion County.

Data cleaning-In examining the height and weight data from the clinical records we found highly improbable patterns, such as a child shrinking five inches in height from one well-child visit to the next. These likely represent clerical errors in data entry. As recommended when conducting secondary analyses of clinical or other health surveillance data, we used algorithms developed by the US Centers for Disease Control and Prevention to identify biologically implausible values for heights and weights (CDC, 2000). We calculated $z$-scores for height and weight measures based on year 2000 US Centers for Disease Control and Prevention (CDC) growth charts. Figure 3 shows the histograms of heights and weights, excluding biologically implausible values with $z$-scores greater than \pm 3.0 .

Visually, there is a small amount of truncation for the heights in the right tail of the height distribution. As can be seen in the second graph, the truncation in the right tail of the body weight distribution is substantial and may reflect exclusion of high weight-for-age children. The CDC Growth Chart reference population spans the period 1963 to 1994, and thus does not fully cover the epidemic in child obesity of the past two decades. Another visual indicator of the extent of the epidemic is how much the distribution has shifted to the right relative to the mean of the reference population. We subsequently revised our rules for biologically implausible values and treated observations with weight-for-height and weight- 
for-age $z$-scores equal to or exceeding +5.0 as outliers likely resulting from data entry error or measurement errors.

Again, the data were restricted to children in the age range 3 through 16. Age was recorded in years since birth. The average age in our sample is 8.26. Additional, we flagged data for biologically implausible values based on CDC growth charts. Children whose BMI z-score (the variable BMIz, based on pre-epidemic mean and standard deviations) were above 5 or below -5 were dropped as being likely data recording errors. The average BMI for the sample is 19.26 .

Summary statistics are presented in Table 2. The variable Well Visit is an indicator variable developed from diagnostic or billing codes suggesting a clinic visit was conducted for well child care and health maintenance instead of seeking treatment for an acute illness. A majority of observations in our dataset come from African American children, while only $29 \%$ of observations are for white children. Over twenty percent of children in our sample are obese. On average, there were 20 counts of Class A violent crimes within a quarter mile of the child's home in a calendar year. We also have median family income data on the census tract in which the child resides. In addition, we are providing summary statistics for two age groups (below and above 8 years). We can see that both BMI and probability of being obese increases with age. Older children are less likely to be seen for a Well Visit. There is also a slight difference in demographic characteristics - lower proportion of older children are Hispanic, but slightly higher proportion are White.

\section{Estimation and Results}

In the base line regression we estimate the direct effect of trails and crime as well as the interaction of the two on children's BMI. We control for age, age squared, race and gender of the child, as well as year and census tract fixed effects. Table 3 has the results of fixed effects regressions on the full sample as well as the breakdown by age, above three and under eight years of age, and for children age eight or more and less than sixteen. We can see that the explanatory power is much higher for the older sample. The R squared is 0.16 for the older sample and 0.06 for the younger. The coefficients on trails are not significant for the younger children but are highly significant for the older children and in the full sample.

If there were no crime near the child's home (thus eliminating the crime term and the interaction with crime and trails), gaining a trail would be beneficial. For example, if a straight line trail were to pass right by an older child's home (thus there would be 800 meters of trail within the quarter mile buffer) it would reduce the child's BMI by $0.200 * 8=$ 1.6 BMI points. For a child of average height among the older children (59 inches) this would translate into a reduction of approximately 8 pounds $(\Delta$-pounds $=\Delta$-BMI $*$ inches $^{\wedge} 2 / 703$ ). Evaluated at the mean length of trails for older children of 14 meters (see Table 2) this effect would be a reduction of 0.14 pounds. However, recall that vast majority of children do not live near a trail. If we evaluate the effect at the average for those living near a trail (200 meters) the effect is a reduction of 2 pounds.

These statistically significant effects of trails are nontrivial. In Sandy et al. (2011), they documented that BMI gains for children were rarely reversed. Previous research finds that other interventions on reducing children's BMI are rarely effective. For example Cawley et al. (2007) find that while state physical education requirements raise the amount of active time during physical education (PE) classes, they do not find evidence that PE lowers BMI. Another example is Millimet et al. (2010), who find that while participation in the National 
School Lunch Program may actually contribute to a rise in childhood obesity, participation in School Breakfast Program could be protective.

Among the observations with a positive amount of trails, the percentage having no crime in a quarter mile is fairly small, $4.3 \%$. Among the observations with no trail within a quarter mile, the proportion with zero crimes within a quarter mile radius is $19.0 \%$. Since almost all of the children in our sample with any nearby trails also have nearby crimes, the combined effect of crime and trails must account for their interaction. Table 4 shows the joint effects of crime and trails on children's BMI at different levels of crime and trail lengths using coefficients for the full sample. The beneficial effect of trails could be greatly reduced by nearby crimes. In the full sample in areas with no crime, an additional hundred meters of trails within a quarter mile buffer around child's home would reduce the child's BMI by 0.144 and the effect is linear. In areas with average level of crimes (20 crimes), the first 100 meters of trails is predicted to increase BMI by 0.02 , but at higher length of trails is predicted to reduce BMI because the trails effect dominates the crime effect. However, in areas with crime above 20 counts, trails are predicted to increase BMI, because crime and interaction of crime and trails are dominating the direct (negative) effect of trails.

The reason for the effects of trails depending so drastically on amount of nearby crimes can be explained using Figure 4. Consider a child living in a low crime area. The child's home is represented by a dot in the middle of the quarter mile buffer around it. Having a short trail in the buffer corresponds to having a trail far from home, which means that the child will have to walk some distance to that trail. Thus, length of trail in part represents the ease of access to the trail. However, if the child lives in a higher crime area, having a longer trail (or a trail closer to home) might mean having more nearby crime, particularly if the trail is used for criminal activity, which in turn might result in less exercise and higher weight. Results in Table 4 show that when the number of crimes equals or more than 30 , any length of trails will raise children's BMI instead of reduce it.

Since we are not controlling for endogeneity of residential choices by families, we cannot claim that the crime coefficients are causal. They could be interpreted as suggestive of children in higher crime areas having fewer opportunities for outdoor play and exercise. But they can also be attributed to the differences in many unobserved characteristics of families who choose to reside in high or low crime areas.

Another broad conclusion looking at the split between younger versus older children is that trails only have a weight reduction benefit among older children, which is intuitive. It is reasonable to assume that the most common trail activities, including walking, biking, jogging, roller blading, are atypical for children ages three through seven. In addition, at its mean level in our full sample across all children with and without access to trails, crime is more important in adding to weight than trails are in reducing it. Crime is significantly directly associated with higher weights for the younger children and through an interaction with trails significantly for the older children.

The remaining regressions split the full sample by levels of crime, income, gender, and into movers and stayers. The results are reported in Table 5. These results show that the beneficial effects of trails are greatest among males who are in higher income areas with below-median levels of crime (below 15 violent crimes per year). We can see that the effects of trails and crime are most pronounced in low crime and higher income areas, as well as among male children. These findings suggest that effects of additional trails and crime are dominated by other factors in higher crime and low income areas. It is also possible that female children do not use trails for exercise as much as male children. 
The last two columns of Table 5 compare results for movers versus stayers. Movers are defined as children who have changed addresses during sample years, while stayers are children who appear at least twice in the dataset and report the same address in all years. Ideally, we would like to be able to distinguish between movers towards the trail and movers away from the trail; however, we were unable to find any effects in these groups because of small sample sizes. While there are some differences in the magnitude of the effects of trails and crime, the fact that all of the coefficients have the same sign is encouraging. While there is a greater weight reduction for trails among the stayers, as one could expect, the difference between the movers and the stayers is small. Coefficient on trails is significant for movers, and it is highly significant for stayers. This result suggests that the weight reduction benefits to the trails would be present if a randomly selected child was given a nearby trail, or equivalently, that the weight reduction is not caused by the movement of families who prefer exercise to locations near a trail.

\section{Falsification test: Do Planned Trails Reduce Child Obesity?}

The regressions in Tables 3 and 5 estimate the effects of built trails on child obesity. Even though the time between the announcement and construction of the built trails was short, these regressions do not rule out the possibility that weight reduction effects were due to the households that most value exercise opportunities relocating near a planned trails before we could observe them in our data, i.e. before they took a child to a clinic visit captured in our data, or that lobbying by households that most valued the trails affected their locations. To address these two possibilities we investigated a counter-factual: what effect do the plannedbut-yet-to-be-constructed trails have on children's weights? If planned trails are associated with weight reductions in a cross-sectional regression, then it is much more likely that our results in Tables 3 and 5 are due to self-selection of households into areas that will gain a trail or exercise-loving households lobbying for trails. Logically, a yet-to-be-built trail cannot reduce children's weights. Conversely, if there is no effect on children's weights from living near planned trails, our results cannot be due to either of these two forms of selfselection. Because the patient data spanned a sufficiently long study period, we were able to analyze BMI changes in areas where trails were built, well before the trail's existence. Table 6 reports the results of a regression that includes planned trails but codes the realized trails at zero.

The pseudo "effect" of announced but yet-to-be-built trails alone is significantly higher BMI overall and for younger children. Crime has the same association as in the regressions with real trails, i.e. crimes have adverse effects on BMI. The interaction of planned trails and crime is negative and significant in all three regressions. The interpretation of the significant interaction terms is that areas with higher crime rates, which will receive trails in the future, on average, have slimmer children. Apparently, the new trails were planned for areas that have higher weight children. This could be interpreted as families with heavier children are lobbying to have better access to trails. But if that is the case our results from previous tables should be interpreted as lower bounds of the "true" effect.

\section{Alternative Measures of Children's Weight Status}

Our main results-that boys in general and children in the age range of 8 to 16 have lower weight if a trail is located within a quarter mile of their homes and that for all children the beneficial effect of trails varies greatly in response to nearby violent crimes-might be sensitive to choice of weight measure. The other commonly used dependent variable is an indicator variable for obesity status. A child with BMI above the $95^{\text {th }}$ percentile of children of the same age and sex during the pre-epidemic cohorts is considered to be obese ${ }^{2}$. Table 7

\footnotetext{
${ }^{2}$ For detailed information, see http://www.cdc.gov/obesity/childhood/defining.html.
} 
duplicates Table 3 but replaces BMI as the dependent variable with an indicator variable for obesity status. These regressions are linear probability models controlling for time and census tract fixed effects. Probit models (available from the authors) yield similar results.

As with the obesity status results, the effect of nearby trails on obesity is greater for the older children than for the younger children. While crime alone always has a positive coefficient, it is only significant in the full sample. On the other hand, trails alone have a negative effect on probability of a child being obese. The interaction between crime and trails is positive in all three regressions and significant in the full sample and the younger children sample. The broad pattern observed in the BMI regressions is also observed in the obesity regressions - trails reduce obesity more for older children and crime increases obesity more for younger children. The effects of trails are particularly pronounce among order children. An additional 100 meters of trails are associated with a reduction the probability of being obese among older children by $1.6 \%$. The magnitude (in absolute value) of this result is comparable to the effect found in other literature. For example, Schanzenbach (2009) found that participation in the National School Lunch Program increases probability of being obese by two to four percentage points.

Table 8 duplicates the regressions found in Table 5 but using obesity indicator instead of BMI. Again, most of the results observed for BMI hold up for obesity. Trails in low crime areas are much more likely to reduce obesity, as are trails in higher income areas. One difference from results in Table 5 is that trails significantly reduce obesity for both male and female children. Lastly, the most interesting of the splits is the movers versus the stayers. Both have similar coefficients in the obesity regressions as in the BMI regressions. Again, this supports the conclusion that the results are not due to households that most value exercise relocating to near a trail.

\section{Conclusions}

In this paper we provide evidence of the effects of recreational trails on children's weight. We argue that the location of trails may be exogenous due to the fact that trails follow riverbanks, an unused canal, and abandoned railways. In addition, we try to account for differential effects of trails depending on levels of crime in the neighborhood. We recognize that families are not randomly selected into low and high crime areas and we do not give causal interpretation to crime coefficients. However, we also recognize that those coefficients are likely to represent the effects of many unobserved family characteristics that govern the residential choice.

We show that recreational trails can have beneficial effects on children's weights in low crime areas, but those effects become detrimental in high crime areas. In addition, we show that the effects differ by age and gender of the child, but are qualitatively similar for both children's BMI and obesity status. We show that in areas with no crime the addition of 100 meters of trails next to a child's home would lead to a reduction of one pound of weight among older children. Since our sample children are mainly from low-income or minority households, our findings may not be nationally representative.

The main contribution of this paper is showing that the effects of trails could be not only different in magnitude among different neighborhoods, but they can also have opposite signs. While many policy makers are interested in finding a solution to the rise in childhood obesity, these solutions might differ by types of populations being targeted. What might have beneficial effects in one area might have opposite effects in another. We are showing that these results can vary substantially within an urban area in Indianapolis, but the differences of the effects of any recreational facility or built environment in general could be 
much larger when comparing urban and suburban settings, as well as different areas of the country.

We study the effects of recreational trails and near-by violent crimes on childhood obesity. We use a unique dataset that consists of data from children's clinic visits, geographical data on length of trails close to the children's homes, and amount of violent crime near child's address. We find that trails have a beneficial effect on childhood obesity in low crime areas, but those effects can be reversed in high crime areas.

\section{Acknowledgments}

We thank Shawn Hoch, Zhang Ya, Megan McDermott, Bikul Tulachan, and Jonathan Raymont for research assistance. This study was funded under NIH NIDDK grant R21 DK075577-01. We thank Kristen Butcher, John Cawley, Daniel Millimet, Deliana Kostova, Gustav Feichtinger, seminar participants at GSU, IUPUI, and University of Aberdeen, Southern Economic Association meetings, IZA conference on the Economics of Risky Behaviors, and three anonymous referees for suggestions and comments.

\section{References}

Agency for Healthcare Research and Quality. Fact Sheet. Rockville, MD: 2010 Jun. Findings on Children's Health Care Quality and Disparities. AHRQ Publication No. 10-P006, http:// www.ahrq.gov/qual/nhqrdr09/nhqrdrchild09.htm

Anderson ML, Matsa DA. Are Restaurants Really Supersizing America? American Economic Journal: Applied Economics. 2011; 3:152-188.

Anderson SE, Whitaker RC. Prevalence of Obesity Among US Preschool Children in Different Racial and Ethnic Groups. Archives of Pediatrics and Adolescent Medicine. 2009; 163(4):344-348. [PubMed: 19349563]

Blum JE, Davee AM, Beaudoin CM, Jenkins PL, Kaley LA, Wigand DA. Reduced Availability of Sugar-Sweetened Beverages and Diet Soda has a Limited Impact on Beverage Consumption Patterns in Maine High School Youth. Journal of Nutrition and Education Behavior. 2008; 40(6): 341-334.

Booth KM, Pinkston MM, Poston WSC. Obesity and the Built Environment. Journal of the American Dietetic Association. 2005; 105:110-117. [PubMed: 15635355]

Burdette HL, Wadden TA, Whitaker RC. Neighborhood Safety, Collective Efficacy, and Obesity in Women with Young Children. Obesity. 2006; 14:518-525. [PubMed: 16648624]

Burdette HL, Whitaker RC. Neighborhood Playgrounds, Fast Food Restaurants, and Crime: Relationships to Overweight in Low-Income Preschool Children. Preventive Medicine. 2004; 38:57-63. [PubMed: 14672642]

Cawley J, Meyerhoefer C, Newhouse D. The Impact of State Physical Education Requirements on Youth Physical Activity and Overweight. Health Economics. 2007; 16(12):1287-1301. [PubMed: 17328052]

Weinstein A, Feigley P, Pullen P, Mann L, Redman L. Neighborhood Safety and the Prevalence of Physical Inactivity-Selected States, 1996. Morbidity and Mortality Weekly Report. 1999; 48(7): 143-148. [PubMed: 10077460]

Committee on Environmental Health. The Built Environment: Designing Communities to Promote Physical Activity in Children. Pediatrics. 2009; 123(6):1591-1598. [PubMed: 19482771]

Duncan DT, Johnson RM, Molnar BE, Azrael D. Association Between Neighborhood Safety and Overweight Status Among Urban Adolescents. BMC Public Health. 2009; 9(298):1-9. [PubMed: 19121216]

Egger G, Swinburn B. An 'Ecological' Approach to the Obesity Pandemic. British Medical Journal. 1997; 315:477-480. [PubMed: 9284671]

Ewing R, Brownson RC, Berrigan D. Relationship Between Urban Sprawl and Weight of United States Youth. American Journal of Preventive Medicine. 2006; 31:464-474. [PubMed: 17169708] 
Ewing R, Schmid T, Killingworth R, Zlot A, Raudenbush S. Relationship Between Urban Sprawl and Physical Activity, Obesity, and Morbidity. American Journal of Health Promotion. 2003; 18:4757. [PubMed: 13677962]

Frank LD, Andresen MA, Schmid TL. Obesity Relationship With Community Design, Physical Activity, and Time Spent in Cars. American Journal of Preventive Medicine. 2004; 27:87-96. [PubMed: 15261894]

French SA, Harnack L, Jeffery RW. Fast Food Restaurant Use Among Women in the Pound of Prevention Study: Dietary, Behavioral and Demographic Correlates. International Journal of Obesity. 2000; 24:1353-1359. [PubMed: 11093299]

Giles-Corti B, Macintyre S, Clarkson JP, Pikora T, Donovan RJ. Environmental and Lifestyle Factors Associated With Overweight and Obesity in Perth, Australia. American Journal of Health Promotion. 2003; 18:93-102. [PubMed: 13677967]

Gordon-Larsen P, Nelson MC, Page P, Popkin BM. Inequality in the Built Environment Underlies Key Health Disparities in Physical Activity and Obesity. Pediatrics. 2006; 117:417-424. [PubMed: 16452361]

Hannon TS, Rao G, Arslanian SA. Childhood Obesity and Type 2 Diabetes Mellitus. Pediatrics. 2005; 116(2):473-480. [PubMed: 16061606]

Hess, Hannah. Illinois lawmaker getting international reaction to 'fat tax' suggestion. www.stltoday.com/news/local/illinois/article_ce1a393c-7b4e-11e0-b418-0019bb30f31a.html.

Hill JO, Peters JC. Environmental Contributions to the Obesity Epidemic. Science. 1998; 280:13711374. [PubMed: 9603719]

Hinkley T, Crawford D, Salmon J, Okely AD, Hesketh K. Preschool Children and Physical Activity: A Review of Correlates. American Journal of Preventive Medicine. 2008; 34:435-441. [PubMed: 18407012]

Jackson RJ, Kochtitzky C. Creating a Healthy Environment: The Impact of the built Environment on Public Health. Sprawl Watch Clearinghouse Monograph Series. 2003

Johnson M. N.C. to Impose 'Fat Tax'. 2009 Oct 7. Retrieved from http://www.newsobserver.com/ 2009/10/07/129651/nc-to-impose-fat-tax.html.

Kantor J. As Obesity Fight Hits Cafeteria, Many Fear a Note from School. New York Times. 2007 Jan 8.

King AC, Jeffery RW, Fridinger F, et al. Environmental and Policy Approaches to Cardiovascular Disease Prevention Through Physical Activity: Issues and Opportunities. Health Education and Behavior. 1995; 22(4):499-511.

Kling JR, Liebman JB, Katz LF, Sanbonmatsu L. Moving to Opportunity and Tranquility: Neighborhood Effects on Adult Economic Self-Sufficiency and Health from a Randomized Housing Voucher Experiment. Princeton IRS Working Paper No. 481. 2004

Li F, Fisher KJ, Brownson RC, Bosworth M. Multilevel Modeling of Built Environment Characteristics Related to Neighborhood Walking Activity in Older Adults. Journal of Epidemiol and Cummunity Health. 2005; 59:558-564.

Librett JJ, Yore MM, Schmid TL. Characteristics of Physical Activity Levels Among Trail Users in a U. S. National Sample. American Journal of Preventive Medicine. 2006; 31:399-405. [PubMed: 17046411]

Lindsey G, Doan NLB. Urban Trails Heavily Used in Indiana. Center for Urban Policy and the Environment, Indiana University Purdue University at Indianapolis (02-C06). 2002

Lindsey G, Wilson J, Yang J, Christopher A. Urban Greenways, Trail Characteristics and Trail Use: Implications for Design. Journal of Urban Design. 2008; Vol. 13(No. 1):53-79.

Liu, GC.; Cunningham, C.; Downs, SM.; Marrero, DG.; Fineberg, N. A Spatial Analysis of Obesogenic Environments for Children; Proceedings of the AMIA Symposium; 2002. p. 459-463.

Lofholm N. Heavy Infant in Grand Junction Denied Health Insurance. 2009 Oct 10. Retrieved from http://www.denverpost.com/ci_13530098.

Lumeng JC, Appugliese D, Cabral HJ, Bradley RH, Zuckerman B. Neighborhood Safety and Overweight Status in Children. Archives of Pediatrics and Adolescent Medicine. 2006; 160:25-31. [PubMed: 16389207] 
Margetts B. WHO Global Strategy on Diet, Physical Activity and Health. Editorial. Public Health Nutrition. 2004; 7:361-363. [PubMed: 15153266]

Merom D, Bauman A, Vita P, Close G. An Environmental Intervention to Promote Walking and Cycling- The Impact of a Newly Constructed Rail Trail in Western Sydney. Preventive Medicine. 2003; 36:235-242. [PubMed: 12590999]

Millimet D, Tchernis R, Hussain M. School Nutrition Programs and the Incidence of Childhood Obesity. Journal of Human Resource. 2010; 45(3):640-654.

Murtagh L, Ludwig DS. State Intervention in Life-Threatening Childhood Obesity. Journal of the American Medical Association. 2011; 306(2):206-207. [PubMed: 21750301]

Nelson MC, Gordon-Larsen P. Physical Activity and Sedentary Behavior Patterns Are Associated With Selected Adolescent Health Risk Behaviors. Pediatrics. 2006; 117:1281-1692. [PubMed: 16585325]

Oliver LN, Hayes MV. Neighborhood Socio-Economic Status and the Prevalence of Overweight Canadian Children and Youth. Canadian Journal of Public Health. 2005; 96:415-420.

Ottensmann JR, Lindsey G. A Use-Based Measure of Accessibility to Linear Features to Predict Urban Trail Use. Journal of Transport and Land Use. 2008; 1:41-63.

Papas MA, Alberg AJ, Ewing R, Helzlsouer KJ, Gary TL, Klassen AC. The Built Environment and Obesity. Epidemiologic Reviews. 2007; 29:129-143. [PubMed: 17533172]

Plantinga AJ, Bernell S. The Association between Urban Sprawl and Obesity: Is It a Two-Way Street? Journal of Regional Science. 2007; 47(5):857-879.

Poston WSC, Foreyt JP. Obesity Is an Environmental Issue. Atherosclerosis. 1999; 146:201-209. [PubMed: 10532676]

Price J, Murnan J, Moore B. Soft Drink Vending Machines in Schools: A Clear and Present Danger. American Journal of Health Education. 2006; 37(5):306-314.

Reynolds KD, Wolch J, Byrne J, Chou C, Feng G, Weaver S, Jerrett M. Trail Characteristics As Correlates of Urban Trail Use. American Journal of Health Promotion. 2007; 21:335-345. [PubMed: 17465179]

Romero AJ, Robinson TN, Kraemer HC, Erickson SJ, Haydel F, Mendoza F, Killen JD. Are Perceived Neighborhood Hazards a Barrier to Physical Activity in Children? Archives of Pediatrics and Adolescent Medicine. 2001; 155:1143-1148. [PubMed: 11576010]

Saelens BE, Sallis JF, Frank LD. Environmental Correlates of Walking and Cycling: Findings from the Transportation, Urban Design, and Planning Literatures. Annals of Behavioral Medicine. 2003; 25:80-91. [PubMed: 12704009]

Salant JD. Coca-Cola, Archer Daniels Fight to Kill Proposed Tax on Sodas. 2009 Jun 27. Retrieved from http://www.bloomberg.com/apps/news?pid=newsarchive\&sid=abiOPaVkntIU.

Sallis JF, Bauman A, Pratt M. Environmental and Policy Interventions to Promote Physical activity. American Journal of Preventive Medicine. 1998; 15:379-397. [PubMed: 9838979]

Sandell C. Too Fat for Health Insurance? At Four Months? 2009 Oct 12. Retrieved from http:// abcnews.go.com/Health/fat-baby-health-insurance/story?id=8812582.

Sandy, R.; Liu, G.; Ottensmann, J.; Tchernis, R.; Wilson, J.; Ford, OT. Studying the Child Obesity Epidemic With Natural Experiments. In: Grossman, M.; Mocan, N., editors. Economic Aspects of Obesity. University of Chicago Press; 2011. p. 181-221.

Schanzenbach D. Does the Federal School Lunch Program Contribute to Childhood Obesity? Journal of Human Resources. 2009; 44:684-709.

Sen, B.; Mennemeyer, S.; Gary, LC. The Relationship Between Neighborhood Quality and Obesity Among Children. In: Grossman, M.; Mocan, N., editors. Economic Aspects of Obesity. Chicago, IL: University of Chicago Press; 2011.

Stafford M, Sacker A, Ellaway A, Cummins S, Wiggins D, Macintyre S. Neighborhood Effects on Health: A Structural Equation Modelling Approach. Journal of Applied Social Science Studies. 2008; 128:109-120.

Swinburn B, Egger G, Raza F. Dissecting Obesogenic Environments: The Development and Application of a Framework for Identifying and Prioritizing Environmental Interventions for Obesity. Preventive Medicine. 1999; 29:563-570. [PubMed: 10600438] 
Trust for America's Health. How Obesity Policies are Failing in America. 2009 Jul. Retrieved from http://healthyamericans.org/reports/obesity2009/. 


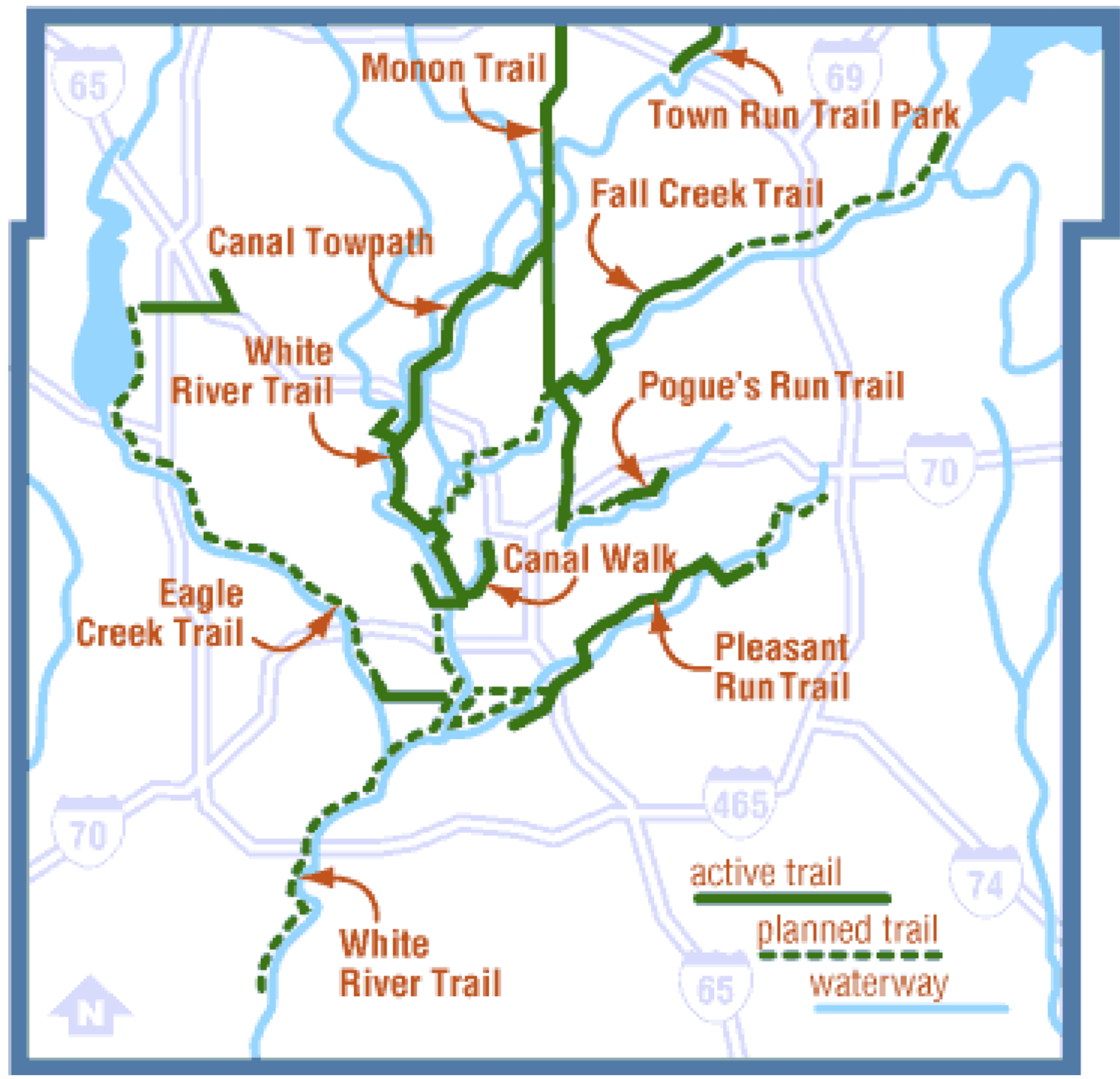

Figure 1.

Trails in Indianapolis 


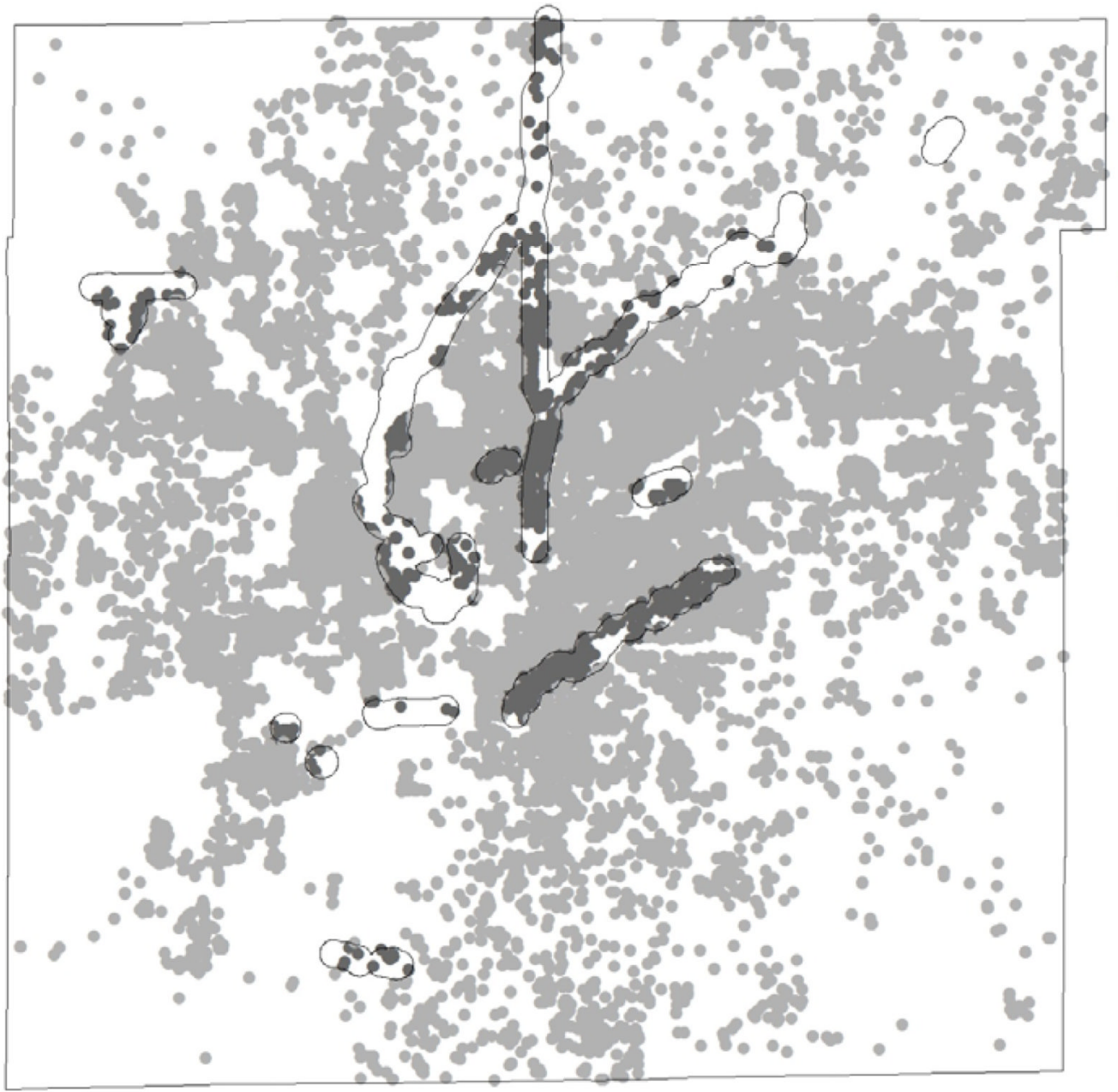

\section{Geocoded Residences}

Outside 0.25 Mile Buffer

- Within 0.25 Mile Buffer

\subsection{Mile Trail Buffer}

Figure 2.

Residential Locations Within and Beyond a Quarter Mile of a Recreational Trail 

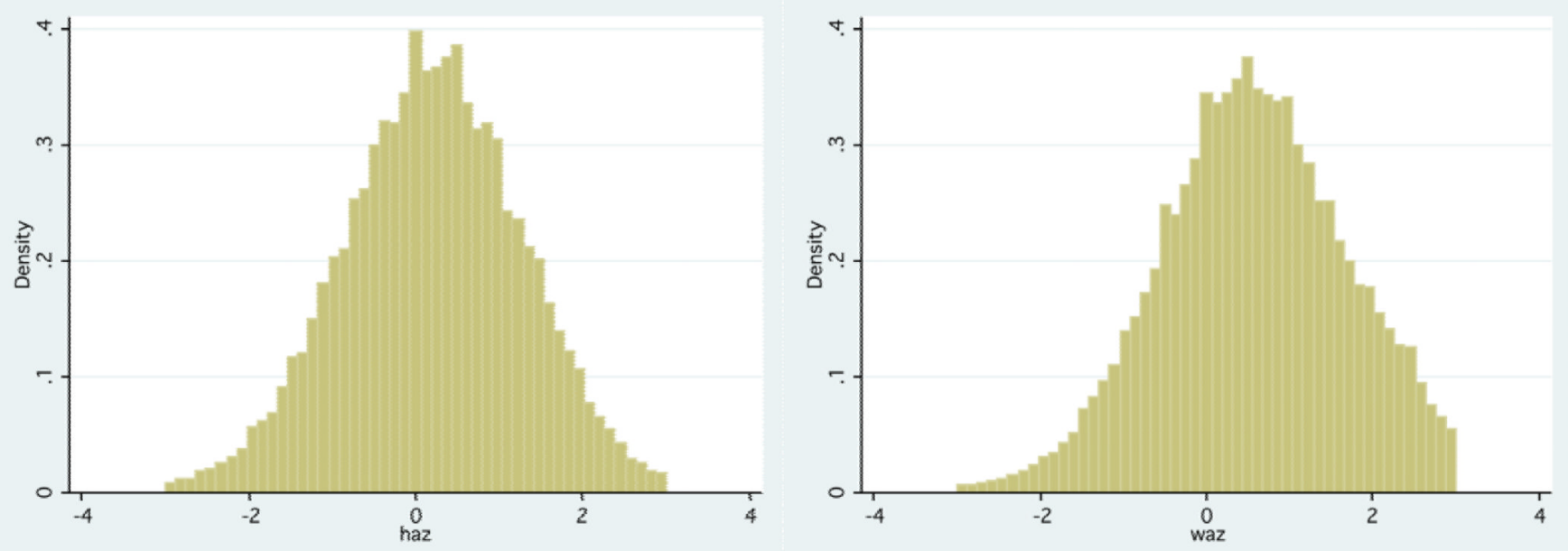

Figure 3.

Histograms of Standardized Height (haz) and Weight (waz) Scores after Dropping Observations with $z$-scores at or Above 3 


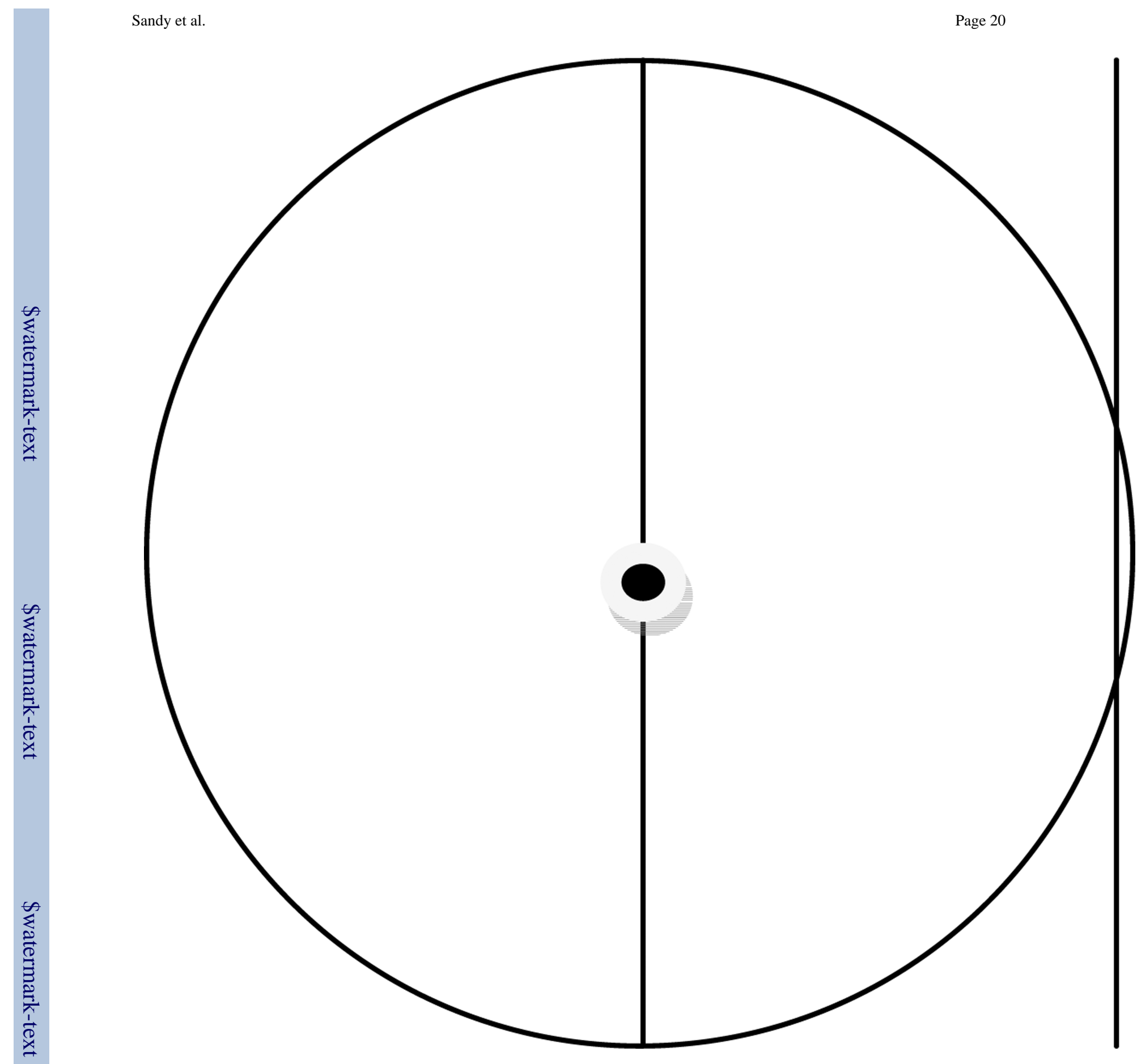

Figure 4.

Locations of Short vs. Long Trails with Relation to Child's Address. 
Table 1

Miles of Trails by Year

\begin{tabular}{ccc}
\hline Year & New Miles & Cumulative Miles \\
\hline 1995 & 5.14 & 5.14 \\
1996 & 3.01 & 8.15 \\
1997 & 11.87 & 20.02 \\
1998 & 11.76 & 31.78 \\
1999 & 1.21 & 32.99 \\
2000 & 2.31 & 35.3 \\
2001 & 2.84 & 38.14 \\
2002 & 1.62 & 39.76 \\
2003 & 4.45 & 44.21 \\
2004 & 1.66 & 45.87 \\
2005 & 1.9 & 47.77 \\
2006 & 4.58 & 52.35 \\
\hline
\end{tabular}

Econ Hum Biol. Author manuscript; available in PMC 2014 January 01. 
Table 3

FE Regressions on BMI

\begin{tabular}{lccc}
\hline & Full sample & Age $<8$ & Age $>8$ \\
\hline trails & $-0.144^{* * *}$ & -0.048 & $-0.200^{* *}$ \\
& $(0.05)$ & $(0.04)$ & $(0.09)$ \\
crime & $0.302^{* * *}$ & $0.324^{* * *}$ & 0.247 \\
& $(0.13)$ & $(0.12)$ & $(0.25)$ \\
trails ${ }^{*}$ crime & $0.517^{* * *}$ & 0.224 & $0.754^{* *}$ \\
& $(0.21)$ & $(0.16)$ & $(0.36)$ \\
Observations & 96,955 & 50,836 & 46,119 \\
R-squared & 0.327 & 0.063 & 0.155 \\
\hline
\end{tabular}

Note: Robust standard errors in parentheses.

significant at $10 \%$;

*** significant at $5 \%$;

**** significant at $1 \%$

All regressions include year and census tract fixed effects.

Control variables: age, agesq, wc, black, hisp, white, female 


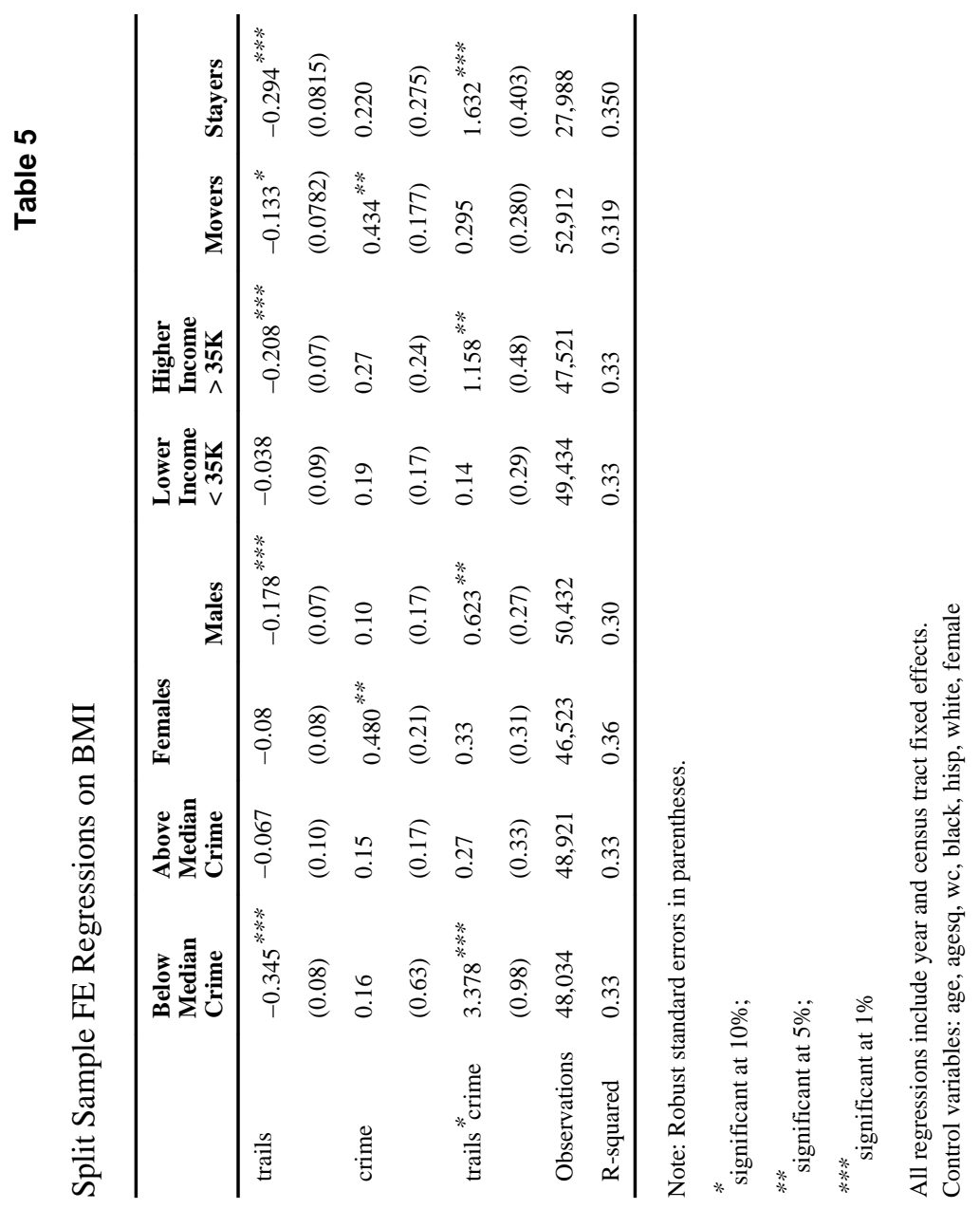

Econ Hum Biol. Author manuscript; available in PMC 2014 January 01. 
Table 6

FE Regressions on BMI for Planned Trails

\begin{tabular}{llll}
\hline & Full sample & Age $<8$ & Age >8 \\
\hline planned trails & $0.0623^{* *}$ & $0.0648^{* *}$ & 0.06 \\
& $(0.03)$ & $(0.03)$ & $(0.06)$ \\
crime & $0.387^{* * *}$ & $0.370^{* * *}$ & 0.35 \\
& $(0.13)$ & $(0.12)$ & $(0.25)$ \\
interaction & $-0.302^{* * *}$ & $-0.158^{*}$ & $-0.466^{* *}$ \\
& $(0.10)$ & $(0.09)$ & $(0.19)$ \\
Observations & 96,955 & 50,836 & 46,119 \\
R-squared & 0.327 & 0.063 & 0.155 \\
\hline
\end{tabular}

Note: Robust standard errors in parentheses.

significant at $10 \%$;

significant at $5 \%$;

**** significant at $1 \%$

All regressions include year and census tract fixed effects.

Control variables: age, age squared, wc, black, hisp, white, female 
Table 7

FE Regressions on Obesity

\begin{tabular}{|c|c|c|c|}
\hline & $\begin{array}{l}\text { Full } \\
\text { sample }\end{array}$ & Age $<8$ & Age $>8$ \\
\hline \multirow[t]{2}{*}{ trails } & $-0.0152^{* * *}$ & $-0.0110^{*}$ & $-0.0160^{* * *}$ \\
\hline & $(0.00)$ & $(0.01)$ & $(0.01)$ \\
\hline \multirow[t]{2}{*}{ crime } & 0.0220 * & 0.02 & 0.02 \\
\hline & $(0.01)$ & $(0.02)$ & $(0.02)$ \\
\hline \multirow[t]{2}{*}{ trails ${ }^{*}$ crime } & $0.0471^{* *}$ & $0.0468 *$ & 0.04 \\
\hline & $(0.02)$ & $(0.02)$ & $(0.03)$ \\
\hline Observations & 96,955 & 50,836 & 46,119 \\
\hline R-squared & 0.029 & 0.028 & 0.023 \\
\hline \multicolumn{4}{|c|}{ Note: Robust standard errors in parentheses. } \\
\hline \multicolumn{3}{|c|}{${ }^{*}$ significant at $10 \%$; } & \\
\hline$* *$ significant at $5 \%$ & $\%$ & & \\
\hline \multicolumn{4}{|c|}{$* * *$ significant at $1 \%$} \\
\hline
\end{tabular}

All regressions include year and census tract fixed effects.

Control variables: age, agesq, wc, black, hisp, white, female 


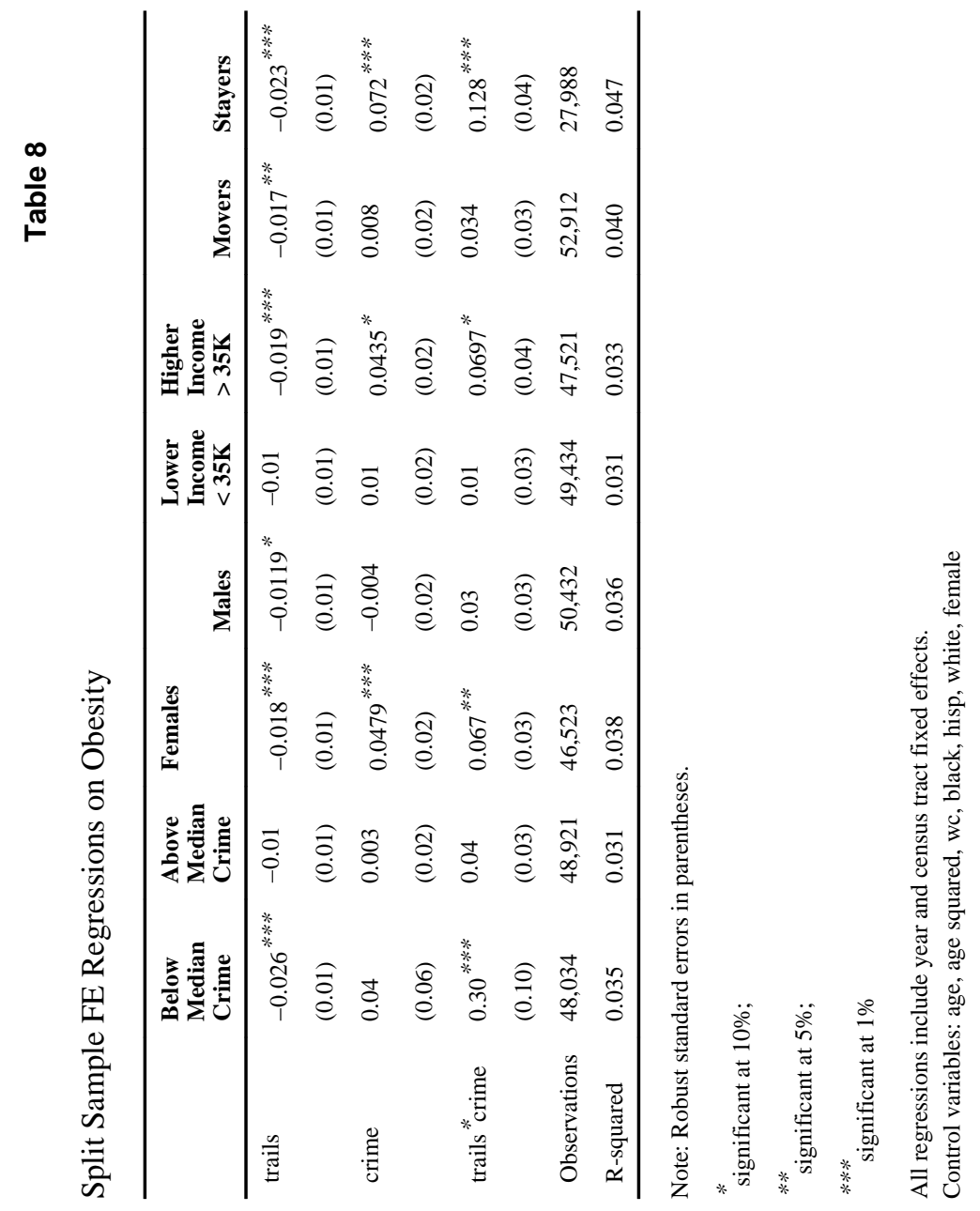

Econ Hum Biol. Author manuscript; available in PMC 2014 January 01. 